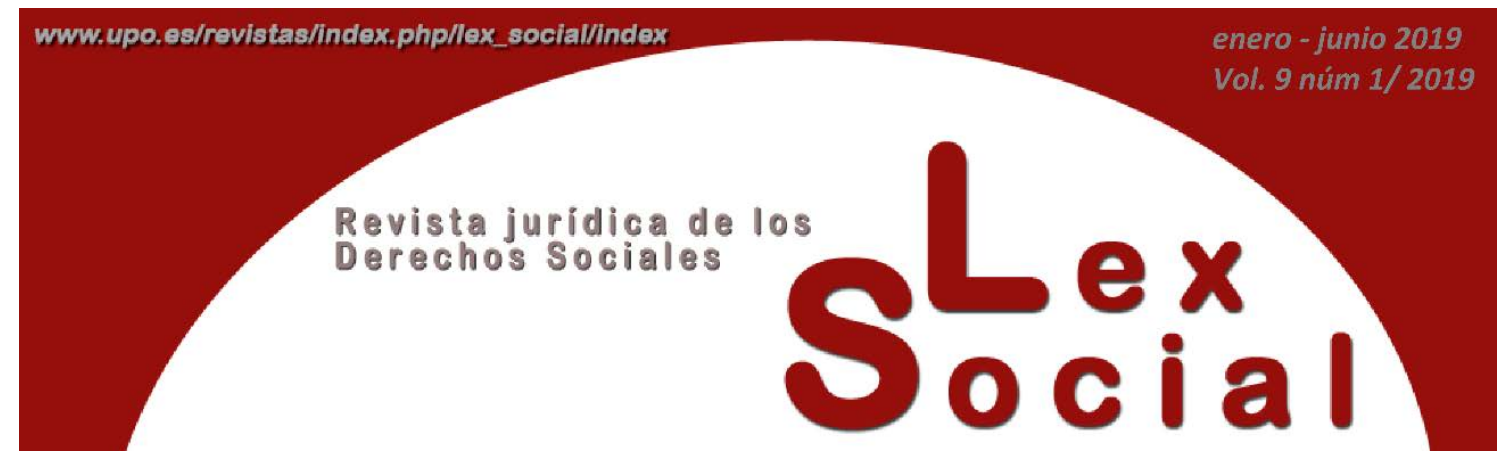

\title{
LA TUTELA DE LAS PERSONAS CON DISCAPACIDAD EN EL DERECHO INTERNACIONAL DE LOS DERECHOS HUMANOS
}

\section{THE PROTECTION OF PERSONS WITH DISABILITIES IN THE INTERNATIONAL LAW OF HUMAN RIGHTS}

\author{
Héctor Álvarez García \\ Profesor Ayudante Doctor de Derecho Constitucional \\ Universidad Pablo de Olavide
}

Artículo recibido el 26 de febrero de 2019

Artículo aceptado el 8 de marzo de 2019

\section{RESUMEN}

El trabajo principia con un recorrido histórico por los distintos modelos implementados por los poderes públicos para abordar el fenómeno de la discapacidad, que culmina con el paradigma social, seña de identidad de la tutela internacional de los derechos de las personas con discapacidad.

El artículo analiza el origen y la evolución del Derecho Internacional de los Derechos Humanos, como exordio al estudio de los convenios sectoriales en materia de protección internacional de las personas con discapacidad, a saber, la Carta Social Europea Revisada, la Convención Interamericana para la Eliminación de todas las Formas de Discriminación contra las Personas con Discapacidad y la Convención sobre los Derechos de las Personas con Discapacidad.

Palabras Clave: Personas con discapacidad, derechos humanos, igualdad, libertad e inclusión social. 


\begin{abstract}
The work begins with a historical journey through the different models implemented by public authorities to address the phenomenon of disability, which culminates with the social paradigm, the hallmark of international protection of the rights of people with disabilities.

The article analyzes the origin and evolution of International Human Rights Law, as an exordium to the study of sectoral agreements on the international protection of persons with disabilities, namely the Revised European Social Charter, the InterAmerican Convention on the Elimination of all Forms of Discrimination against Persons with Disabilities and the Convention on the Rights of Persons with Disabilities.
\end{abstract}

KEY WoRDs: People with disabilities, human rights, equality, freedom and social inclusion.

\title{
SUMARIO
}

\section{Introducción.}

2. Los paradigmas históricos de la discapacidad.

\subsection{Eugenésico.}

\subsection{Médico.}

\subsection{Social.}

3. El Derecho Internacional de los Derechos Humanos.

\subsection{La Carta Social Europea Revisada.}

3.2. La Convención Interamericana para la Eliminación de todas las Formas de Discriminación contra las Personas con Discapacidad.

3.3. La Convención sobre los Derechos de las Personas con Discapacidad.

\section{Bibliografía.}

A Manuel Terol, gran maestro y mejor persona, in memoriam 


\section{Introducción}

Las personas somos biológicamente diferentes pero jurídicamente iguales porque la dignidad humana es un atributo ingénito a todo viviente racional y libre. Las facultades cognoscitivas y volitivas nos singularizan, identifican y diferencian respecto a los demás seres vivos y nos hacen acreedores o titulares de una serie de derechos fundamentales, cuyo objeto es garantizar y potenciar nuestra libertad moral.

Sin embargo, la Historia de la humanidad es el relato de la desigualdad. Desde la noche de los tiempos, el hombre se ha servido del poder y del derecho para establecer factores de diferenciación social (riqueza, poder, religión, nacionalidad, sexo, nacimiento, etc.,) que institucionalizaron el principio de acepción de persona: privilegios para los minoritarios grupos sociales dominantes y la discriminación secular de la inmensa mayoría de la población.

El Nuevo Régimen, inaugurado por las revoluciones liberales, se forjó sobre la ideología constitucional, que preconiza como objetivo o punto de destino la construcción de un modelo de sociedad que gravite sobre la igualdad y la libertad. El constitucionalismo de primera hora -netamente liberal- tuvo que cabalgar contradicciones internas; por una parte, el movimiento codificador europeo plantó la semilla de la igualdad formal ${ }^{1}$, caracterizada por la abolición de los privilegios y la generalidad de la ley; pero, por otra, aceptó la esclavitud, el sufragio censitario y condenó al ostracismo social a numerosos grupos sociales como las mujeres, las personas con discapacidad o los pobres.

La teoría ilustrada de la dignidad se construye sobre las capacidades humanas, la utilidad social y la naturaleza instrumental de los derechos. La dignidad era un atributo que se asignaba a aquellas personas que alcanzaban el grado socialmente estimado en el desarrollo de sus capacidades racionales, comunicativas y sensitivas. Ello implicaba que su actividad beneficiaría a la sociedad y, por tanto, había que reconocerles derechos públicos subjetivos que promocionaran, estimularan y protegieran esas capacidades en orden a que las personas rindieran los mejores frutos.

Sensu contrario, aquellas personas que presentaran deficiencias en sus capacidades eran una carga social. No eran dignas y, por tanto, no eran titulares originarios de derechos y sólo podían recibir caridad o asistencialismo gracioso por parte del Estado para cubrir sus necesidades de subsistencia.

En cambio, la dignidad en la teoría de los derechos fundamentales es un atributo o grandeza consustancial a toda persona -por su cualidad de agente racional y libre- con independencia de que se aproxime o se aleje del patrón de normalidad físico-psíquica fijado en un determinado momento histórico.

El respeto a la dignidad de las personas con discapacidad exige el reconocimiento de su libertad moral, característica predicable de todos ciudadanos, y que se concreta en

\footnotetext{
${ }^{1}$ El paradigma de la igualdad en el Estado liberal implicó un notable avance respecto a la discriminación jurídica del Antiguo Régimen, pero en modo alguno combatió o atemperó los desequilibrios o desigualdades sociales presentes en la sociedad, ya que las normas no tenía en cuenta las circunstancias singulares de los grupos sociales.
} 
la facultad para autodeterminarse, para forjar su propio destino vital mediante la adopción autónoma de decisiones personalísimas. Para ello, los poderes públicos han de abandonar las tradicionales políticas públicas heterónomas -paternalistas, proteccionistas y asistenciales-, basadas en el paradigma de la incapacidad de la persona para autogobernarse y que exige la constante asistencia de un tercero, el tutor, que asume la dirección de su vida.

La garantía de la dignidad humana reclama no sólo el reconocimiento de la titularidad formal de los derechos, sino especialmente la igualdad en el ejercicio de los mismos por parte de las personas con discapacidad, cuya finalidad es asegurar una vida buena a todos los ciudadanos. Los derechos son un instrumento al servicio de la libertad moral de las personas, sin los cuales no podríamos autodeterminarnos: orientar nuestra existencia a la consecución de los objetivos predefinidos ${ }^{2}$.

La igualdad preconizada por el constitucionalismo social y democrático no es sinónimo de igualitarismo, ni de identidad -tratar a todos por igual-, sino de igualdad material o proporcional: tratar igual a los iguales y desigual a los desiguales, es decir, "la igualdad es la razonabilidad de la diferencia jurídica”, que legitima "un derecho desigual a fin de garantizar a los individuos y grupos vulnerables o en desventaja socioeconómica la igualdad de oportunidades”3.

La construcción del Estado social es un imperativo o mandato constitucional a los poderes públicos. Así, pues, el legislador debe transformar la sociedad por medio de la implementación del denominado Derecho antidiscriminatorio, que estriba sobre la igualdad de trato -prohibición de la discriminación directa e indirecta-, cuyo objeto es la extinción de los factores de discriminación históricos; y la igualdad de oportunidades -acciones positivas y medidas de discriminación inversa ${ }^{4}$-, cuya finalidad es corregir o atenuar las desventajas o desigualdades socioeconómicas que restringen agudamente el libre desarrollo de la personalidad.

\section{Los paradigmas históricos de la discapacidad}

\subsection{Eugenésico}

El sistema de organización político-social de las ciudades-estado de la Antigüedad se fundamentó en la doctrina organicista del poder: la comunidad política -el todo- es

\footnotetext{
${ }^{2}$ Cfr. ASÍS, R. de, "Derechos humanos y discapacidad. Algunas reflexiones derivadas del análisis de la discapacidad desde la teoría de los derechos”, en CAMPOY CERVERA, I. y PALACIOS, A., Igualdad, no discriminación y discapacidad, Dykinson, Madrid, 2007, pp. 30-48.

${ }^{3}$ REY MARTÍNEZ, F., "Igualdad y prohibición de discriminación: de 1978-2018”, Revista de Derecho Político, No100, 2018, p. 129.

4 “(...) se refiere a un trato jurídico diferente y favorable a los miembros de un grupo fácticamente desaventajado que (a diferencia de las acciones positivas) simétricamente produce un trato jurídico concreto diferente y peor a uno o varios miembros del grupo mayoritario" (Ibidem, p. 144).
} 
anterior y, por tanto, superior y más valiosa que el individuo -la parte ${ }^{5}$-, el cual debe sacrificar sus intereses privados en favor del bien común de la colectividad.

“El reconocimiento del carácter orgánico del Estado es la única fuente de la idea de que la comunidad es algo valioso en sí mismo. Y sólo del valor superior del todo comparado con sus partes puede derivarse la obligación de los ciudadanos de vivir para ese todo y, en caso necesario, de morir por él” ${ }^{6}$.

La libertad individual de los antiguos era plena en la vida pública: participaban directamente en la adopción de las decisiones políticas que afectaban a la ciudad. Sin embargo, en los asuntos privados empalidecía ante los intereses generales que anegaban la autonomía de la voluntad, sujeta a la ley.

“Todas las acciones privadas están sometidas a una vigilancia severa. Nada está concedido a la independencia individual, ni bajo la relación de las opiniones, ni bajo la de la industria, -ni sobre todo bajo la religión-. (...) las leyes regulan las costumbres, y las costumbres lo gobiernan todo. No hay nada que no regulen las leyes.

Así, entre los antiguos, el individuo, soberano casi habitual en los asuntos públicos, es esclavo en todas sus relaciones privadas" ${ }^{7}$.

La ciudad era un organismo armónico, formado por diversas partes perfectamente articuladas. Cada ciudadano debía realizar eficientemente la función que le había sido asignada por la ley en orden a asegurar el bienestar del cuerpo político, la tranquilidad pública $^{8}$.

La vigencia de la teoría política organicista explica que en la Antigüedad la vida humana fuera valiosa en tanto que útil a la comunidad, es decir, sólo se valoraba al ciudadano ideal: aquél que respondía al patrón de normalidad biológica que le permitiera cumplir eficientemente con su función social.

\footnotetext{
5 "Por naturaleza, pues, la ciudad es anterior a la casa y a cada uno de nosotros, porque el todo es necesariamente anterior a la parte. En efecto, destruido el todo, ya no habrá ni pie ni mano, a no ser con nombre equívoco, como se puede decir una mano de piedra: pues tal será una mano muerta” (ARISTÓTELES, Política, 1252b).

${ }^{6}$ GIERKE, O., Das Wesen der menschlichen Verbande (1902), f. 34, citado por KELSEN, H., Teoría general del Derecho y del Estado, UNAM, México, 1995, p. 221.

${ }^{7}$ CONSTANT, B., "De la libertad de los antiguos comparada con la de los modernos”, §3 y 4 (conferencia pronunciada en el Ateneo Royal de París en 1819).

8 “(...) asentemos con Aristóteles que la ciudad es como una naturaleza animada o animal. Porque como el animal bien constituido según su naturaleza se compone de ciertas partes ordenadas entre sí con proporción, y con sus funciones combinadas entre sí y en orden al todo, así la ciudad se forma de determinadas partes cuando está bien constituida según razón. (...) la salud (...) es la disposición buena del animal, en la cual cada uno de sus miembros puede ejercitar perfectamente las acciones propias de su naturaleza; y según esta analogía la tranquilidad será la buena disposición de la ciudad o del reino, en la cual cada una de sus partes puede realizar perfectamente las operaciones convenientes a su naturaleza, según la razón y su constitución. (...) la intranquilidad será la mala disposición de la ciudad o del reino, como la enfermedad del animal, por la cual están impedidos todos o algunos de sus miembros para hacer sus operaciones propias, o tomados aparte absolutamente, o en su conjunto y funcionamiento total” (PADUA, M. de, El Defensor de la Paz, I, $2, \S 3)$.
} 
La concepción de la ciudad como un ser vivo implicaba la expurgación de los miembros inútiles: aquéllos que menoscaban el vigor del cuerpo político al requerir constantes cuidados, y no contribuían a robustecer ninguna de las partes constitutivas de la ciudad.

Así, pues, el infanticidio fue una práctica eugenésica defendida por egregios filósofos clásicos -Aristóteles ${ }^{9}$ y Platón ${ }^{10}$-, generalizada en Grecia y Roma y justificada por razones religiosas ${ }^{11} \mathrm{y}$ de utilidad: la crianza de un niño con discapacidad congénita constituía una pesada carga para la familia y la sociedad debido a su inutilidad. No iba a aportar nada al bien común.

En Atenas, el método empleado para materializar el infanticidio consistía en someter al recién nacido a una inhumana prueba de resistencia: se colocaba al bebé en un recipiente y se le abandonaba durante diez días fuera de la ciudad. Si conseguía sobrevivir al hambre y a las alimañas significaba que gozaba de la protección de los dioses, en cuyo caso era recogido y criado por sus progenitores.

En Esparta, todos los recién nacidos eran examinados por el Consejo de ancianos al objeto de verificar que cumplían con el estándar biológico exigible para afrontar en el futuro las funciones sociales, esencialmente marciales, a las que eran convocados los espartanos. Si no superaba el examen médico el bebe era lanzado desde el Monte Taigeto.

En la Roma republicana, sobre la base del principio de patrimonialidad de la descendencia, la Ley de las XII Tablas autorizaba al paterfamilias a matar al hijo nacido con deformidad (IV Tabla). Está práctica eugenésica, sin embargo, estaba arraigada desde la fundación de la Ciudad Eterna y continuó durante la etapa imperial.

Adviértase que la ciudad-estado ateniense fue la primera comunidad política en reconocer el derecho a percibir una prestación económica a las personas con discapacidad sobrevenida por causa de guerra, accidente o enfermedad, como mecanismo de retribución o compensación por los servicios prestados a la ciudad ${ }^{12}$.

\footnotetext{
9 "En cuanto a la exposición o crianza de los hijos, debe ordenarse que no se críe a ninguno defectuoso" (ARISTÓTELES, op. cit., 1335b).

10 "Digo, pues, que ya ha sido sentado el principio de que los mejores de cada sexo deben unirse con los mejores con tanta frecuencia, y los inferiores con los inferiores tan rara vez, como sea posible; y que es preciso criar a los vástagos del primer tipo de unión, pero no del segundo, si la estirpe se ha de mantener en condiciones óptimas (...). Los funcionarios pertinentes llevarán los hijos de los padres selectos al redil o guardería, y allí los depositarán en manos de ciertas nodrizas que habitarán un cuarto separado; pero los vástagos de los inferiores, o de los superiores cuando hayan nacido deformes, serán rechazados (...)” (PLATÓN, Gorgias, Carta Séptima).

11“(...) el nacimiento de un niño o niña con diversidad funcional era el resultado de un pecado cometido por los padres en el caso de Grecia, o la advertencia de que la alianza con los dioses se encontraba rota en el caso de Roma" (SANTAYANA, G., "El peso de la historia: la evolución de los modelos de diversidad funcional”, en PALACIOS, A. y ROMAÑACH, J., El modelo de la diversidad: la bioética y los derechos humanos como herramientas para alcanzar la plena dignidad en la diversidad funcional, Diversitas, Madrid, 2006, p. 41).

${ }^{12}$ Cfr. PALACIOS, A., El modelo social de discapacidad: orígenes, caracterización y plasmación en la Convención Internacional sobre los Derechos de las personas con discapacidad, Ediciones Cinca, Madrid, 2008, pp. 37-50.
} 
Durante el Antiguo Régimen, por influjo del cristianismo toda vida humana tenía valor en sí misma y no en virtud de su utilidad, por tanto, debía ser cuidada y protegida. Se abandonaron las prácticas eugenésicas y se creó una cierta conciencia social sobre la necesidad de procurar un mínimo sustento vital a los pobres ${ }^{13}$, categoría social integrada en un número significativo por personas con discapacidad.

Sin embargo, a pesar de estos cambios las personas con discapacidad siguieron sufriendo el estigma de la maldición divina y eran abandonadas por sus progenitores en los hospicios eclesiásticos, donde se les intentaba procurar un sustento básico para sobrevivir, lo cual no impedía que debido a la escasez de medios muchos murieran por falta de las atenciones necesarias. Estas personas estaban condenadas a la mendicidad o a servir de vil entretenimiento en la Corte como bufones.

A partir de finales del siglo XIX, con la irrupción de las revolucionarias teorías darwinianas sobre la evolución de las especies y la selección natural, se desató un creciente interés por mejorar y perfeccionar al ser humano por medio de las políticas públicas eugenésicas ${ }^{14}$, arraigando especialmente en los países anglosajones, el área germánica y la Europa del Norte ${ }^{15}$.

El caso alemán fue el más trágico: la idea de terminar con la vida de las personas con discapacidad germinó en los años veinte. Binding, penalista alemán, y Hoche, profesor de psiquiatría de la Universidad de Friburgo, publicaron en 1920 un estremecedor opúsculo titulado La autorización para exterminar a los seres humanos desprovistos de valor vital. Estos autores sostenían que "en el interés de todo el organismo humano, los miembros menos valiosos deben ser abandonados y eliminados," y que "un día no lejano llegaremos a la conclusión de que la eliminación de los espiritualmente muertos es un acto permisible y necesario" 16 .

En 1933, con la llegada del nacionalsocialismo al poder, se aprobó la Ley de evitación de la descendencia morbosa. En octubre de 1939, Hitler inició el programa Aktion T-4, en el que conminaba a todos los médicos del III Reich a ejecutar "muertes por compasión”. El resultado fue que los nazis esterilizaron a cerca de medio millón de personas y asesinaron sistemáticamente a varios cientos de miles de personas con discapacidad ${ }^{17}$.

\footnotetext{
${ }^{13}$ Cfr. VIVES, L., Tratado del socorro de los pobres, Marcial Pons, Madrid, 2007.

${ }^{14}$ El término eugenesia fue acuñado por el primo de Darwin, Francis Galton, en 1883. Abogaba por implementar políticas públicas dirigidas a impedir la degeneración de la raza sajona. Cfr. RUIZ GUTIÉRREZ, R. y SUÁREZ Y LÓPEZ GUAZO, L., Eugenesia, herencia, selección y biometría en la obra de Francis Galton, Revista ILUIL, vol. 25, 2002.

${ }^{15}$ Durante el primer tercio del siglo XX, una treintena de Estados Norteamericanos aprobaron leyes de esterilización forzosa de mujeres con deficiencias intelectuales. Al otro lado del Atlántico, diversos países europeos siguieron el mismo camino en los años veinte: Suiza, Suecia, Dinamarca y Noruega.

${ }^{16}$ Citado por TALE, C., "La discriminación de los discapacitados en el derecho a la vida: la sinrazón de sus argumentos”, Revista Telemática de Filosofía del Derecho, Nº 9, 2005/2006, p. 166, nota 2.

${ }^{17}$ Cfr. GARCÍA MARCOS, J. A., La eutanasia en la Alemania nazi y su debate en la actualidad, UNED, Valencia, 2009 y MÜLLER, T. y BEDDIES, T., "Eutanasia y eugenesia en la Alemania de Weimar y el Tercer Reich”, en MONTIEL, L. y GARCÍA ALONSO, M., Pensar el final: la eutanasia, Editorial Complutense, Madrid, 2007, pp. 79-90.
} 


\subsection{Médico}

Después de la Segunda Guerra Mundial, el fenómeno de la discapacidad se afronta desde el paternalismo, el asistencialismo y la institucionalización. Las limitaciones físicas, psíquicas y sensoriales no son causadas por la voluntad divina sino que responden a razones científicas: constituyen el resultado de una patología que provoca una restricción en la funcionalidad de la persona, en relación con los parámetros socialmente establecidos.

La discapacidad era entendida como un problema o afección que concernía exclusivamente a la persona. Su valor social dependía de que se rehabilitara y fuera útil para la comunidad. Los poderes públicos contribuyeron a la reinserción social y a combatir la pobreza de los ciudadanos con discapacidad por medio del reconocimiento de un conjunto de derechos sociales de naturaleza prestacional y económica: educación especial, empleo protegido, sistema público de salud, servicios asistenciales y el régimen público de la seguridad social.

La persona con discapacidad estaba sujeta a la voluntad ajena: médicos y familiares la privaban de su capacidad de autogobierno ${ }^{18}$. Debía seguir los tratamientos impuestos durante el proceso de normalización, cuya finalidad era ingresar en la sociedad, pensada y diseñada para el ciudadano que respondiera al patrón de biológico medio, es decir, era la persona la que tenía que adaptarse al entorno y si no podía o era inviable su recuperación se la institucionalizaba de por vida.

La comunidad estaba exonerada de cualquier tipo de responsabilidad u obligación. Se limitaba a ofrecer soluciones exclusivamente médicas, claramente insuficientes y perniciosas para conseguir la inclusión política, económica y social de las personas con discapacidad.

La construcción teórica del modelo médico o rehabilitador se fundamenta en la ideología que Stiker denomina the social ideal of erasure -el ideal de la goma de borrar, en virtud de la cual la imposición de un determinado paradigma físico-psíquico lleva a la invisibilidad social de las diferencias y necesidades de las personas con discapacidad, cristalizando en la construcción de un entorno hostil ${ }^{19}$.

La política pública que nos ilustra vivamente esta reflexión es el modelo de accesibilidad a los servicios públicos del ciudadano medio, pretiriendo al resto de la

\footnotetext{
18 “(...) desde el punto de vista médico presenta tres dimensiones: a) la patrimonial, en el sentido de autonomía e independencia en la actividad socioeconómica, b) la adaptativa e interpersonal, relativa a la capacidad de afrontar los problemas de la vida diaria en la forma y manera que sería de esperar para su edad y contexto sociocultural, y c) la personal, que se corresponde con la capacidad para desenvolverse eficazmente dentro de su entorno, manteniendo una existencia independiente por ser capaz de satisfacer por sí mismo el individuo las necesidades físicas más inmediatas, básicamente alimentación, higiene y autocuidado" (RODRÍGUEZ CARO, $\mathrm{M}^{\mathrm{a}} \mathrm{V}$. "La incapacitación: nuevo enfoque jurisprudencial de la protección de las personas con discapacidad. Novedades en la Ley de la Jurisdicción Voluntaria y en el ámbito penal”, p. 2, https://goo.gl/8rIL0T, fecha de consulta: 14/12/2018).

${ }^{19}$ Cfr. ASÍS, R. de, BARIFFI, F. y PALACIOS, A., "Principios éticos y fundamentos jurídicos", en LORENZO, R. de y PÉREZ BUENO, L. C., (coord.), Tratado sobre discapacidad, Aranzadi, Madrid, 2007, p. 87.
} 
población que por diversas causas no entra en este concepto apolíneo que presupone unas capacidades y habilidades de las que carece un importante número de ciudadanos.

En efecto, no sólo resultan postergadas las personas con discapacidad permanente, sino también muchas otras limitadas coyunturalmente en su funcionalidad ordinaria: embarazadas, lesionados en período de rehabilitación, familias con hijos pequeños, personas obesas, personas que cargan bultos, adultos mayores, etc., sufren la restricción de sus derechos fundamentales al conculcarse sus posibilidades de interacción social.

\subsection{Social}

El Movimiento de Vida Independiente, artífice intelectual o ideológico del enfoque social de la discapacidad, surgió al calor de las reivindicaciones por los derechos civiles de la población negra en los Estados Unidos en el gozne de la década de los sesenta y setenta.

El precursor de la lucha contra la discriminación de las personas con discapacidad en Norteamérica fue Ed Robert. Este joven estudiante universitario, cuya vida dependía de un pulmón artificial, superó todas las dificultades impuestas por los poderes públicos para terminar sus estudios universitarios en Ciencia Política.

El éxito de Robert en sus demandas de accesibilidad universitaria fue el germen del Movimiento de Vida Independiente, cuyas reivindicaciones de inmediato de extendieron a todos los ámbitos de la vida social. Su ideario se cifraba en la libertad de las personas con discapacidad para decidir sobre las cuestiones que afectaran a su propia vida $^{20}$.

El modelo social considera la discapacidad como una forma de opresión o sometimiento social que se ejerce sobre el conjunto de personas que difieren del patrón de normalidad biológica.

"Para entenderlo es necesario comprender la distinción entre la deficiencia física y la situación social, a la que se llama «discapacidad», de las personas con tal deficiencia. Así, definimos la deficiencia como la carencia total o parcial de un miembro, o la posesión de un miembro, órgano o mecanismo defectuosos; y la discapacidad es la desventaja o la limitación de la actividad causada por una organización social contemporánea que tiene en escasa o en ninguna consideración a las personas con deficiencias, y por tanto, las excluye de participar en las actividades sociales generales. La discapacidad es, por consiguiente, una forma particular de opresión”21

\footnotetext{
${ }^{20}$ Cfr. SANTAYANA, G., op. cit., pp. 49-55.

21 “Principios fundamentales de la Discapacidad”, Manifiesto de la Unión de los Físicamente Impedidos contra la Discriminación, Londres, 1976, citado por MOSCOSO, M., "La discapacidad como diversidad funcional: los límites del paradigma etnocultural como modelo de justicia social”, Dilemata, No 7, 2011, p. 78.
} 
La causa que socava la libertad moral ${ }^{22}$ de este grupo social no es la deficiencia, sino que es la sociedad la que realmente le impide el libre desarrollo de su personalidad ${ }^{23}$. Es el naufragio de la sociedad que no ha sabido o querido adaptarse a las necesidades de todos los ciudadanos ${ }^{24}$. Los cambios -la normalización- deben operarse sobre el medio social para construir una sociedad plenamente democrática, donde se respeten los derechos y las libertades de todos.

El modelo social parte de la concepción de la deficiencia como una diferencia, igual que el género o la raza. Rechaza connotaciones negativas o peyorativas y aboga por una visión positiva y optimista de la deficiencia, al considerarla como un rasgo más de la persona, como un elemento enriquecedor de la diversidad y heterogeneidad de la especie humana.

Se fundamenta en la acción social y política: la primera se refiere a la responsabilidad que tiene la sociedad de remover los obstáculos y eliminar todas las barreras, incluidas las psicológicas, que impiden la plena participación en la vida pública de las personas con deficiencias. Y la segunda se dirige a la obligación que tienen los poderes públicos de garantizar el ejercicio de sus derechos en condiciones de igualdad con los demás ciudadanos.

Este nuevo enfoque modifica sustancialmente la estrategia política y social de la discapacidad: de los tratamientos rehabilitadores, del asistencialismo y la perenne tutela estatal y familiar, propios del modelo médico, a la gestión de los apoyos y la adaptación del medio a las deficiencias.

El papel de la sociedad es nuclear en la misión de conseguir la plena inclusión de los ciudadanos con deficiencias. Hay que superar la pasividad y la neutralidad de tiempos pretéritos y abogar por un posicionamiento activo y enérgico de la comunidad política en orden a favorecer el pleno disfrute de sus derechos, a los que son acreedores por su condición de personas.

"La sociedad, en efecto, no es sólo el escenario en el que acontece el problema, sino que es un personaje importante del drama. La sociedad discapacita y rehabilita, segrega y agrega. La sociedad, por ello, ha de ser objeto

\footnotetext{
22 “(...) el art. 1.1 de la Constitución consagra la libertad como «valor superior» del ordenamiento jurídico español, lo que implica, evidentemente, el reconocimiento, como principio general inspirador del mismo, de la autonomía del individuo para elegir entre las diversas opciones vitales que se le presenten, de acuerdo con sus propios intereses y preferencias" (STC 132/1989, de 18 de julio, FJ. $6^{\circ}$ ).

23 "La discapacidad surge de una deficiencia que existe dentro de la sociedad, que es la que crea las barreras que impiden la integración y el entendimiento" (Declaración del Foro Europeo de la Discapacidad, octubre de 1994).

24 “El problema radica en el fracaso de la sociedad y del entorno creado por el ser humano para ajustarse a las necesidades y aspiraciones de las personas con discapacidad, y no en la incapacidad de dichas personas para adaptarse a las demandas de la sociedad" (HARLAN HAHN, adalid del movimiento por los derechos de las personas con discapacidad en Estados Unidos, "Public support for rehabilitation programs: the analysis of US Disability Policy”, Disability, Handicap \& Society, vol. 1, № 2, 1986, p. 128).
} 
de intervenciones que la hagan cada vez menos agresiva y más accesible, menos áspera y más hospitalaria, menos normativa y más tierna”25.

La sociedad es responsable del acontecer relativo a la discapacidad: es un agente provocador de resultados -positivos o negativos-, de forma que no puede sustraerse a su responsabilidad. Debe tener una voluntad inequívoca de constituirse en parte impulsora y favorecedora del cambio y de la transformación de la situación actual por medio de la acción directa de las instituciones y demás entidades representativas del cuerpo social, que están legitimadas para modificar la realidad y conseguir los objetivos de integración y pleno desarrollo de la personalidad de los ciudadanos con deficiencias.

\section{El Derecho Internacional de los Derechos Humanos}

La experiencia histórica de la primera mitad del siglo XX puso de manifiesto como señala Pastor Ridruejo- que "era el propio Estado el primer y más importante violador de los derechos del hombre” y que “existía una relación innegable entre el respeto a los derechos humanos dentro de los Estados y el mantenimiento de la paz en la comunidad internacional”.

Así, pues, la barbarie devastadora de las dos guerras mundiales supuso un punto de inflexión en el derecho internacional público: frente a la concepción clásica, caracterizada por la indiferencia hacia el trato que los Estados dispensaban a sus nacionales y por la fijación de un estándar mínimo de protección respecto a los ciudadanos extranjeros (personas físicas y jurídicas), de forma que en caso de vulneración "se articulaba la sanción por el mecanismo de la responsabilidad internacional del Estado infractor y la protección diplomática del Estado de la nacionalidad de la víctima”; la humanización del derecho internacional contemporáneo gravita sobre el desarrollo del derecho internacional humanitario y el respeto y garantía de los derechos humanos, cifrada en la "imposición de obligaciones de los Estados respecto a todos los individuos, nacionales o extranjeros, y en que los individuos puedan reclamar directamente contra el Estado infractor ante instancias internacionales en caso de vulneración de sus derechos" ${ }^{26}$.

La Carta de las Naciones Unidas de 1945 anuncia en el Preámbulo su firme compromiso con los derechos fundamentales, la igualdad, la dignidad y el valor de la vida humana. En el corpus jurídico del Tratado destacan los artículos 1.3, 55.c y 56, en los que se impone a todos los Estados el deber de adoptar las medidas precisas en orden a garantizar el respeto y la efectividad universal de los derechos y libertades fundamentales.

\footnotetext{
25 CASADO PÉREZ, D, "Prólogo” a PANTANO, L., La discapacidad como problema social, Buenos Aires, Eudeba, 1987, citado por BENARDELLI, B., “Accesibilidad al medio físico y comunicacional”, en Discapacidad en Argentina: un diagnóstico de situación y políticas pública vigentes a 2005, Fundación Par, Buenos Aires, 2006, p. 114.

${ }^{26}$ PASTOR RIDRUEJO, J.A., Curso de Derecho Internacional Público y Organizaciones Internacionales, Tecnos, Madrid, 2003, pp. 195-196.
} 
La ausencia de un catálogo preciso de derechos humanos en la Carta se supliría tres años después con la aprobación de la Declaración Universal de los Derecho Humanos (1948), adoptada por la Resolución de la Asamblea General de las Naciones Unidas, de 10 de diciembre de 1948, con cuarenta y ocho votos a favor y ocho abstenciones. Sin entrar en el agudo debate sobre la naturaleza jurídica de la misma, en el que existen posiciones a favor y en contra de considerarla un instrumento vinculante para los Estados miembros de la comunidad internacional ${ }^{27}$. Lo que está fuera de toda duda es su extraordinaria influencia tanto en la configuración del derecho internacional de los derechos humanos como en el constitucionalismo democrático.

A partir de este hito histórico, la Organización de Naciones Unidas ha efectuado una excepcional labor de codificación en materia de derechos del hombre. En primer lugar, ha desarrollado los derechos civiles, políticos, económicos, sociales y culturales enunciados en la Declaración Universal en dos tratados internacionales de alcance universal: los Pactos Internacionales de 1966 y sus dos Protocolos facultativos, que conforman en su conjunto la Carta Internacional de los Derechos Humanos.

La dicotomía de los derechos del hombre en civiles y políticos y económicos y sociales está reñida con el principio de indivisibilidad de los derechos humanos, caracterizado por la interdependencia, la complementación y la igualdad entre todos los derechos al estar radicados en la dignidad humana, por lo que repudia la jerarquización y, por tanto, la prevalencia de unos derechos sobre otros.

Esta división fue debida a la fractura del mundo en dos bloques enfrentados y antagónicos. En efecto, mientras que los Estados democráticos consideraban prioritarios los derechos civiles y políticos, los Estados autoritarios de corte marxista y socialista no sólo pretendían -con cierto cinismo- dar preferencia a los derechos sociales, económicos y culturales, sino que además se posicionaron en contra de aceptar las reclamaciones individuales contra los Estados ante el Comité de Derechos Humanos por la violación de los derechos civiles y políticos, lo que provocó que la articulación de este mecanismo de control tuviera que ser regulado en un Protocolo de aceptación voluntaria al margen del Pacto Internacional de Derechos Civiles y Políticos.

“Las estructuras socioeconómicas injustas se mantienen generalmente gracias a la represión, esto es, mediante la vulneración de los derechos civiles y políticos más elementales; además, esas violaciones suelen provocar acciones revolucionarias y estas últimas intensifican a su vez las acciones de represión; y en la revolución y subsiguiente represión las violaciones de derechos civiles y políticos alcanzan niveles extremos" ${ }^{28}$.

En segundo lugar, mediante la adopción de numerosos convenios sectoriales, entre los que destacamos los considerados, junto con los Pactos Internacionales de 1966,

\footnotetext{
${ }^{27}$ Cfr. NOVAK TALAVERA, F., "La Declaración Universal de los Derechos Humanos cincuenta años después”, Agenda Internacional, Vol. 4, №10, 1998.

${ }^{28}$ PASTOR RIDRUEJO, J.A., op. cit., p. 222.
} 
Tratados fundamentales de los derechos humanos: Convención sobre la Eliminación de todas las Formas de Discriminación Racial (1965), Convención contra la Tortura (1984), Convención sobre la Eliminación de todas las Formas de Discriminación contra la Mujer (1979), Convención sobre los Derechos del Niño (1989), Convención Internacional para la Protección de Todas las Personas contra las Desapariciones Forzadas (2006), la Convención sobre los Derechos de las Personas con Discapacidad (2006) y la Convención Internacional sobre la Protección de los Derechos de Todos los Trabajadores Migratorios y los Miembros de sus Familias (2003).

Este corpus jurídico tuitivo de los derechos del hombre se caracteriza por que todos los convenios están dotados de tres mecanismos de control y garantía que se residencian en los respectivos comités, a saber, el sistema de informes periódicos, la reclamación de un Estado contra otro y las denuncias individuales de las víctimas contra el Estado infractor.

Finalmente, debemos reseñar la importancia de los instrumentos jurídicos regionales: la Convención Europea de Derechos Humanos (1950) y la Carta Social Europea Revisada (1996), fraguados en el seno del Consejo de Europa, la Convención Interamericana de Derechos Humanos (1969) y la Carta Africana de Derechos Humanos (1981).

\subsection{La Carta Social Europea Revisada}

Este Tratado internacional del Consejo de Europa, denominado Constitución Social Europea, actualiza el contenido sustantivo de la Carta Social Europea (1961) para adaptarlo a los cambios y demandas sociales producidos en las últimas décadas en el Viejo Continente.

Se estructura en tres partes: en la primera, los Estados se comprometen a adoptar las medidas adecuadas para la consecución de treinta y uno objetivos de política social. Nos encontramos ante obligaciones de comportamiento y no de resultado, ergo, los Estados gozan de un amplio margen de apreciación o discrecionalidad política para modular el reconocimiento de los mismos en atención a la coyuntura económica y social.

En la segunda parte se desarrolla el contenido sustantivo de los derechos enunciados en la primera, configurados como obligaciones de resultado. Y, finalmente, la tercera favorece la aplicación gradual de la Carta y atiende a la diversidad de Estados que integran el Consejo de Europa, en orden a permitir una gran flexibilidad a los Estados parte en la determinación de los derechos por los que se sienten vinculados ${ }^{29}$.

\footnotetext{
${ }^{29}$ Parte III. “A.1.b. a considerarse obligada por al menos seis de los nueve artículos siguientes de la Parte II de la Carta: artículos 1, 5, 6, 7, 12, 13, 16, 19 y 20.

A.1.c. a considerarse obligada por un número adicional de artículos o párrafos numerados de la Parte II de la Carta que ella elija, siempre que el número total de los artículos y de los párrafos numerados a los que quedará obligada no sea inferior a dieciséis artículos o a sesenta y tres párrafos numerados”.
} 
El punto décimo quinto de los objetivos de política social de la Carta se refiere al derecho a la autonomía, a la integración social y a la participación en la vida de la comunidad de las personas con discapacidad. Este precepto tiene su fiel reflejo en el artículo 15 de la segunda parte, sin perjuicio de que en los artículos 9 y 10 haya un par de alusiones a las personas con discapacidad en relación a la orientación y la formación profesional.

"Para garantizar a las personas minusválidas, con independencia de su edad y de la naturaleza y el origen de su minusvalía, el ejercicio efectivo del derecho a la autonomía, a la integración social y a la participación en la vida de la comunidad, las Partes se comprometen, en particular:

1.-) a tomar las medidas adecuadas para procurar a las personas minusválidas orientación, educación y formación profesional en el marco del régimen general, siempre que sea posible, o, en caso contrario, a través de instituciones especializadas, ya sean públicas o privadas;

2.-) a promover su acceso al empleo mediante todas las medidas encaminadas a estimular a los empleadores para que contraten y mantengan empleadas a las personas minusválidas en el entorno habitual de trabajo y a adaptar las condiciones de trabajo a las necesidades de los minusválidos o, cuando ello no sea posible por razón de la minusvalía, mediante el establecimiento o la creación de empleos protegidos en función del grado de incapacidad. Estas medidas pueden exigir, en determinados casos, el recurso a servicios especializados de colocación y de apoyo;

3.-) a promover su plena integración y participación social, en particular, mediante la aplicación de medidas, incluidas las ayudas técnicas, dirigidas a superar las barreras a la comunicación y a la movilidad y a permitirles acceder a los transportes, a la vivienda, y a las actividades culturales y de ocio”.

Los treinta y cuatro Estados que han ratificado la Carta Social Europea Revisada desde que fue abierta a la firma en 1996 -entre los que lamentablemente no se encuentra España a pesar de ser definida en el primer artículo de la Constitución como un Estado social $^{30}$ - se han comprometido a adoptar las medidas precisas para garantizar a este nutrido grupo social el derecho a la educación y a la formación profesional en régimen general, siempre que sea posible, de forma que la segregación será la excepción y no la norma. Asimismo, han asumido el compromiso internacional de favorecer el acceso de las personas con discapacidad al empleo en condiciones de igualdad que el resto de los

\footnotetext{
${ }^{30}$ El Consejo de Ministro acordó el pasado 1 de febrero remitir a las Cortes Generales la Carta Social Europea Revisada sin incluir el Protocolo Adicional sobre el procedimiento de reclamaciones colectivas, que constituye la garantía fundamental de los derechos sociales recogidos en la Carta, en orden a obtener la autorización para su ratificación, de conformidad con lo previsto en el artículo 94.1 de la Constitución.
} 
trabajadores, de manera que el sistema de empleo protegido será la ultima ratio en el caso de que la discapacidad de la persona le impida desenvolverse en un entorno laboral convencional. Y, finalmente, deben promover la accesibilidad universal de modo que se supriman las barreras de toda laya que impiden a las personas con discapacidad el ejercicio de sus derechos fundamentales.

Siguiendo a Blanco Egido, el grado de tutela de los derechos sociales y económicos que ofrece la Carta es insuficiente debido a que "no se trata la perspectiva de la discapacidad transversalmente en el resto del articulado ni siquiera en algunos, en los que por las necesidades de estas personas estaría especialmente justificado"; por otra parte, el artículo 15 es incompleto en la enumeración de las carencias y problemas a los que se enfrentan cotidianamente las personas con discapacidad; y, finalmente, resulta evidente la despreocupación de la Carta por los derechos de las personas con discapacidad cuando ninguno de los tres artículos en los que se menciona a este relevante grupo social aparecen recogidos en el listado de los nueve preceptos fundamentales de Tratado ${ }^{31}$.

\subsection{La Convención Interamericana para la Eliminación de todas las Formas de Discriminación contra las Personas con Discapacidad}

El Sistema Interamericano de Derechos Humanos principió a preocuparse por la tutela de las personas con discapacidad en el Protocolo de San Salvador de 1988. Esta norma jurídica incorporó al Pacto de San José de Costa Rica de 1969 los derechos sociales, económicos y culturales. En efecto, el artículo 18 manifiesta una cierta preocupación por mejorar la calidad de vida de las personas con discapacidad, pero desde una perspectiva médica, segregadora y limitada, que era la imperante en el momento histórico en que se debatió el articulado del Protocolo.

La singularidad de la Convención Interamericana para la Eliminación de todas las Formas de Discriminación contra las Personas con Discapacidad, aprobada por la Asamblea General de la Organización de Estados Americanos en 1999, reside en su originalidad y en el cambio de paradigma de la discapacidad. En efecto, fue el primer instrumento jurídico internacional que se preocupó de la protección de los derechos de las personas con discapacidad sobre la base de un enfoque diverso en el estudio del fenómeno de la discapacidad: el modelo social.

“El término «discapacidad» significa una deficiencia física, mental o sensorial, ya sea de naturaleza permanente o temporal, que limita la capacidad de ejercer una o más actividades esenciales de la vida diaria, que puede ser causada o agravada por el entorno económico y social”32.

\footnotetext{
${ }^{31}$ BLANCO EGIDO, E., “La protección jurídica en el ámbito del Consejo de Europa”, en LORENZO, R. de y PÉREZ BUENO, L. C., (coord.) Tratado sobre discapacidad, Navarra, 2007, pp. 418-419.

${ }^{32}$ Art. 1.1.
} 
En cuanto a su estructura y naturaleza jurídica, si bien nos encontramos ante un tratado internacional y, por tanto, de innegable fuerza vinculante, en realidad, una vez examinado el corpus del Convenio, apreciamos que nos encontramos propiamente con una norma de soft law, es decir, impone obligaciones de conducta y no de resultado.

Los objetivos del Tratado son la prevención y la eliminación de todas las formas discriminación contra las personas con discapacidad y propiciar su plena inclusión social; sin embargo, no señala medidas concretas que deban ser adoptadas por los Estados parte, "sino que detalla áreas y metas”33; "ni consagra expresamente derechos de las personas con discapacidad ni obligaciones -prohibiciones o mandatos - de los Estados”34.

\subsection{La Convención sobre los Derechos de las Personas con Discapacidad}

La Convención sobre los Derechos de las Personas con Discapacidad, firmada en Nueva York el 13 de diciembre de 2006, constituye el primer instrumento jurídico internacional de alcance universal sobre esta materia ${ }^{35}$. Vino precedido de la aprobación de varios textos políticos de naturaleza programática por la Asamblea General de las Naciones Unidas, a saber, la Declaración de los Derechos del Retrasado Mental (1971); la Declaración de los Derechos de los Impedidos (1975), los Principios para la Protección de los Enfermos Mentales y para el Mejoramiento de la Atención de la Salud Mental (1991) y las Normas Uniformes sobre la igualdad de oportunidades para las personas con discapacidad $(1993)^{36}$.

El Convenio sobre los derechos de las personas con discapacidad, así como los demás tratados internacionales ratificados por España que inciden sobre los derechos fundamentales, están revestidos de una fuerza activa y pasiva; esto significa, por una parte, que desde su incorporación al derecho interno español mediante su publicación en

\footnotetext{
${ }^{33}$ Artículo III: “a) Medidas para eliminar progresivamente la discriminación y promover la integración por parte de las autoridades gubernamentales y/o entidades privadas en la prestación o suministro de bienes, servicios, instalaciones, programas y actividades, tales como el empleo, el transporte, las comunicaciones, la vivienda, la recreación, la educación, el deporte, el acceso a la justicia y los servicios policiales, y las actividades políticas y de administración;

b) Medidas para que los edificios, vehículos e instalaciones que se construyan o fabriquen en sus territorios respectivos faciliten el transporte, la comunicación y el acceso para las personas con discapacidad;

c) Medidas para eliminar, en la medida de lo posible, los obstáculos arquitectónicos, de transporte y comunicaciones que existan, con la finalidad de facilitar el acceso y uso para las personas con discapacidad; d) Medidas para asegurar que las personas encargadas de aplicar la presente Convención y la legislación interna sobre esta materia, estén capacitados para hacerlo".

${ }^{34}$ COURTIS, C., "Los derechos de las personas con discapacidad en el Sistema Interamericano de Derechos Humanos”, en LORENZO, R. de y PÉREZ BUENO, L. C., (coord.) Tratado sobre discapacidad, Navarra, 2007, pp. 456 y 457.

${ }^{35}$ La Convención fue ratificada por España el 3 de diciembre de 2007 e incorporada a nuestro derecho interno por medio de su publicación en el Boletín Oficial del Estado el 21 de abril de 2008.

36 "Aunque no son de cumplimiento obligatorio, estas Normas pueden convertirse en normas internacionales consuetudinarias cuando las aplique un gran número de Estados con la intención de respetar una norma de derecho internacional. Llevan implícito el firme compromiso moral y político de los Estados de adoptar medidas para lograr la igualdad de oportunidades” (\$14).
} 
el Boletín Oficial del Estado prevalecen sobre todas aquellas leyes que los contradigan fuerza activa-; y por otra, que sus disposiciones no pueden ser derogadas o modificadas por ninguna norma jurídica (fuerza pasiva), sino que tal y como establece el artículo 96.1 de la Constitución, "sus disposiciones sólo podrán ser derogadas, modificadas o suspendidas en la forma prevista en los propios tratados o de acuerdo con las normas generales del derecho internacional”.

La primacía del Tratado sobre las fuentes formales de nuestro Ordenamiento jurídico exigió la adaptación del mismo a sus preceptos, mediante la Ley 26/2011, de 1 de agosto, de adaptación normativa a la Convención Internacional sobre los Derechos de las Personas con Discapacidad.

Por imperativo del artículo 10.2 de la Constitución ${ }^{37}$, este Convenio internacional tiene valor hermenéutico respecto a los derechos fundamentales reconocidos en la Sección primera del Capítulo segundo del Título primero de nuestra Norma Suprema. Lo que significa que sus disposiciones nutren o integran su contenido esencial, indisponible para el legislador orgánico.

Este aspecto jurídico tiene una gran relevancia práctica en dos cuestiones centrales para la libertad moral de las personas con discapacidad. La primera es la inconstitucionalidad de la privación del derecho de sufragio activo de las personas incapacitadas judicialmente o ingresadas en un hospital psiquiátrico con autorización judicial -art. 3.1.b y c de la LOREG- por vulnerar el artículo 23 de la Constitución (derecho a participar en los asuntos públicos), interpretado de conformidad con el artículo 29 del Convenio, que reconoce el derecho a la participación política de las personas con discapacidad en igualdad de condiciones con las demás ${ }^{38}$.

Esta histórica discriminación se ha erradicado finalmente gracias a la promulgación de la Ley Orgánica 2/2018, de 5 de diciembre, para garantizar el derecho de sufragio de todas las personas con discapacidad.

Esta norma jurídica ha reformado la LOREG en tres puntos: derogación del artículo 3.1.b y c; modificación del artículo 3.2 para reconocer a toda persona el ejercicio del derecho de sufragio activo, consciente, libre y voluntariamente, cualquiera que sea su forma de comunicarlo y con los medios de apoyo que requiera; e introducción de la disposición adicional octava en la que se reintegra el derecho de sufragio a todas aquellas

\footnotetext{
37 “Las normas relativas a los derechos fundamentales y a las libertades que la Constitución reconoce se interpretarán de conformidad con la Declaración Universal de los Derechos Humanos y los tratados y acuerdos internacionales sobre las mismas materias ratificados por España”.

${ }^{38}$ Resulta esclarecedor el Voto particular discrepante de la Magistrada del Tribunal Constitucional, Adela Asúa Batarrita, respecto al Auto 196/2016, de 28 de noviembre, dictado por la Sección Tercera del Alto Tribunal, que sorprendentemente inadmitió un recurso de amparo sobre esta materia aduciendo manifiesta ausencia de lesión del derecho fundamental a participar en los asuntos públicos.
} 
personas con discapacidad que en virtud de sentencia judicial firme habían sufrido una limitación o supresión del mismo.

La segunda es la probable inconstitucionalidad de la esterilización forzosa, prevista en el artículo 156.2 del Código Penal ${ }^{39}$, por conculcar el artículo 15 de la Norma Suprema (derecho a la integridad física y moral), interpretado de acuerdo con el artículo 23 del Convenio, que reconoce el derecho de todas las personas con discapacidad para decidir sobre su fertilidad en igualdad de condiciones que las demás.

En el pórtico del Convenio reza su principal objetivo: “(...) promover, proteger y asegurar el goce pleno y en condiciones de igualdad de todos los derechos humanos y libertades fundamentales por todas las personas con discapacidad, y promover el respeto de su dignidad inherente" 40 .

El Convenio no es una declaración programática sino que tiene un carácter jurídico vinculante. Marc un claro cambio ideológico en el tratamiento de la discapacidad. Sitúa en un primer lugar las políticas integradoras propias del modelo social y relega a un segundo plano las deficiencias físicas, psíquicas o sensitivas en que se materializa la discapacidad.

El Tratado considera que la discapacidad resulta "de la interacción entre las personas con deficiencias y las barreras debidas a la actitud y al entorno que evitan su participación plena y efectiva en la sociedad, en igualdad de condiciones con las demás”41. Esta manera de entenderla supone una ruptura radical con el modelo médico y una apuesta decidida por el modelo social, que considera la discapacidad como un complejo conjunto de condiciones, muchas de las cuales son creadas o agravadas por la sociedad, impidiendo a las personas con deficiencias el ejercicio de sus derechos.

El tratamiento de la discapacidad desde la perspectiva de los derechos fundamentales es la gran aportación jurídico-política del Convenio. Constituye la punta de lanza en el ámbito internacional contra la discriminación secular de este colectivo ${ }^{42}$. Se caracteriza por reformular los derechos fundamentales que forman parte del acervo jurídico-constitucional de los Estados democráticos, teniendo en cuenta la diversidad que presenta este grupo social, y haciendo especial hincapié en la garantía de su eficacia en orden a que los Estados Parte implementen las acciones positivas oportunas que hagan posible el ejercicio autónomo de sus derechos y dejen de ser personas con un déficit de ciudadanía.

\footnotetext{
39 “No será punible la esterilización acordada por órgano judicial en el caso de personas que de forma permanente no puedan prestar en modo alguno el consentimiento al que se refiere el párrafo anterior, siempre que se trate de supuestos excepcionales en los que se produzca grave conflicto de bienes jurídicos protegidos, a fin de salvaguardar el mayor interés del afectado, todo ello con arreglo a lo establecido en la legislación civil”.

${ }^{40}$ Artículo 1.

${ }^{41}$ Preámbulo, §e.

42 "Reconociendo también que la discriminación contra cualquier persona por razón de su discapacidad constituye una vulneración de la dignidad y el valor inherentes del ser humano” (Preámbulo, §h).
} 
“Los principios de la presente Convención serán: el respeto de la dignidad inherente, la autonomía individual, incluida la libertad de tomar las propias decisiones, y la independencia de las personas; la no discriminación; el respeto por la diferencia y la aceptación de las personas con discapacidad como parte de la diversidad y la condición humana; la igualdad de oportunidades; la accesibilidad; la igualdad entre el hombre y la mujer"43.

Como consecuencia de la filosofía del modelo social y del principio de igualdad que inspiran el Convenio, el artículo 12 establece que las personas con discapacidad "tienen capacidad jurídica en igualdad de condiciones con las demás en todos los aspectos de la vida” y que los Estados Parte deben procurarles el acceso al "apoyo que puedan necesitar en el ejercicio de su capacidad jurídica”.

Este precepto implica una revolución copernicana en los sistemas tuitivos de las personas con discapacidad vigentes en los ordenamientos jurídicos democráticos, porque "unifica la capacidad jurídica y de obrar en un todo inseparable, como sucede en cualquier persona, y a partir de esta necesaria igualdad, proporcionarle los mecanismos de apoyos adecuados. Así, se asegura a la persona con discapacidad su plena capacidad para crear, modificar o extinguir relaciones jurídicas y se restringe el instrumento de la incapacitación si afecta a la anulación de la capacidad de obrar”44.

El Convenio consagra el principio de autonomía de la voluntad de las personas con discapacidad al objeto de potenciar al máximo su autodeterminación, "porque la capacidad de decidir es la puerta de acceso a todo el catálogo de derechos constitucionales, sin la cual se convierten en meras proclamas retóricas y vacías de contenido real”45. Preconiza la sustitución del sistema de consentimiento por representación, propio del modelo médico, por un modelo de apoyos respetuoso con la libertad moral de los ciudadanos con limitaciones funcionales ${ }^{46}$.

\section{Bibliografía}

ARISTÓTELES, Política, introducción, traducción y notas de Manuela García Valdés, Gredos, Madrid, 1988.

\footnotetext{
43 Artículo 3.

${ }^{44}$ STS 282/2009, de 29 de abril, FJ. $3^{\circ}$.

45 BARIFFI, F., "Introducción a la Mesa Redonda: Plena igualdad ante la Ley, capacidad jurídica y limitación de derechos”, en Conferencia Internacional 2008-2013: cinco años de vigencia de la Convención Internacional sobre los derechos de las personas con discapacidad, CERMI, 2014, p. 5.

${ }^{46}$ Cfr. BARRANCO, M. del C., CUENCA, P. y RAMIRO, M. A., "Capacidad jurídica y discapacidad: el artículo 12 de la convención de derechos de las personas con discapacidad”, Anuario de la Facultad de Derecho, Universidad de Alcalá, 2012, pp. 54-69.
} 
ASÍS, R. de, "Derechos humanos y discapacidad. Algunas reflexiones derivadas del análisis de la discapacidad desde la teoría de los derechos”, en CAMPOY CERVERA, I. y PALACIOS, A., Igualdad, no discriminación y discapacidad, Dykinson, Madrid, 2007.

Ibid., BARIFFI, F. y PALACIOS, A., “Principios éticos y fundamentos jurídicos”, en LORENZO, R. de y PÉREZ BUENO, L. C., (coord.), Tratado sobre discapacidad, Aranzadi, Madrid, 2007.

BENARDELLI, B., “Accesibilidad al medio físico y comunicacional”, en Discapacidad en Argentina: un diagnóstico de situación y políticas pública vigentes a 2005, Fundación Par, Buenos Aires, 2006.

BLANCO EGIDO, E., “La protección jurídica en el ámbito del Consejo de Europa”, en LORENZO, R. de y PÉREZ BUENO, L. C., (coord.) Tratado sobre discapacidad, Navarra, 2007.

CAMPOY CERVERA, I. y PALACIOS, A., Igualdad, no discriminación y discapacidad, Dykinson, Madrid, 2007.

CONSTANT, B., "De la libertad de los antiguos comparada con la libertad de los modernos”, en Escritos Políticos. Benjamin Constant, estudio preliminar, traducción y notas de María Luisa Sánchez-Mejía Rodríguez, Centro de Estudios Políticos y Constitucionales, Madrid, 1989.

COURTIS, C., "Los derechos de las personas con discapacidad en el Sistema Interamericano de Derechos Humanos”, en LORENZO, R. de y PÉREZ BUENO, L. C., (coord.) Tratado sobre discapacidad, Aranzadi, Navarra, 2007.

GARCÍA MARCOS, J. A., La eutanasia en la Alemania nazi y su debate en la actualidad, UNED, Valencia, 2009.

KELSEN, H., Teoría general del Derecho y del Estado, UNAM, México, 1995.

HARLAN HAHN, "Public support for rehabilitation programs: the analysis of US Disability Policy”, Disability, Handicap \& Society, vol. 1, Nº 2, 1986.

MOSCOSO, M., "La discapacidad como diversidad funcional: los límites del paradigma etnocultural como modelo de justicia social”, Dilemata, № 7, 2011.

MÜLLER, T. y BEDDIES, T., "Eutanasia y eugenesia en la Alemania de Weimar y el Tercer Reich”, en MONTIEL, L. y GARCÍA ALONSO, M., Pensar el final: la eutanasia, Editorial Complutense, Madrid, 2007.

NOVAK TALAVERA, F., "La Declaración Universal de los Derechos Humanos cincuenta años después”, Agenda Internacional, Vol. 4, Nº10. 
PADUA, M. de, El Defensor de la Paz, estudio preliminar, traducción y notas de Luis Martínez Gómez, Tecnos, Madrid, 2009.

PALACIOS, A., El modelo social de discapacidad: orígenes, caracterización y plasmación en la Convención Internacional sobre los Derechos de las personas con discapacidad, Ediciones Cinca, Madrid, 2008.

PASTOR RIDRUEJO, J.A., Curso de Derecho Internacional Público y Organizaciones Internacionales, Tecnos, Madrid, 2003.

PLATÓN, Gorgias, Rialp, Madrid, 2014.

REY MARTÍNEZ, F., “Igualdad y prohibición de discriminación: de 1978-2018”, Revista de Derecho Político, №100, 2018.

RODRÍGUEZ CARO, Ma .V. "La incapacitación: nuevo enfoque jurisprudencial de la protección de las personas con discapacidad. Novedades en la Ley de la Jurisdicción Voluntaria y en el ámbito penal”. https://goo.gl/8rIL0T

RUIZ GUTIÉRREZ, R. y SUÁREZ Y LÓPEZ GUAZO, L., Eugenesia, herencia, selección y biometría en la obra de Francis Galton, Revista ILUIL, vol. 25, 2002.

SANTAYANA, G., "El peso de la historia: la evolución de los modelos de diversidad funcional”, en PALACIOS, A. y ROMAÑACH, J., El modelo de la diversidad: la bioética y los derechos humanos como herramientas para alcanzar la plena dignidad en la diversidad funcional, Diversitas, Madrid, 2006.

TALE, C., "La discriminación de los discapacitados en el derecho a la vida: la sinrazón de sus argumentos”, Revista Telemática de Filosofía del Derecho, No 9, 2005/2006.

VIVES, L., Tratado del socorro de los pobres, Marcial Pons, Valencia, 1992. 